\title{
Epidemiology of Oral Candidiasis in HIV-Infected Patients: Colonization, Infection, Treatment, and Emergence of Fluconazole Resistance
}

Jon A. Sangeorzan, MD, Suzanne F. Bradley, MD, Xiaogang He, MD, Lidija T. Zarins, MS, George L. Ridenour, BA, Robert N. Tiballi, DO, Carol A. Kauffman, MD, Ann Arbor, Michigan

PURPOSE: To study the epidemiology of oral candidiasis and the effect of treatment of thrush in human immunodeficiency virus (HIV)-infected patients.

PATIENTS AND METHODS: We conducted a prospective observational study of 92 patients over 1 year, including a nonblinded, randomized treatment trial of thrush with clotrimazole troches or oral fluconazole. Oral sites were cultured monthly and when thrush occurred. Candida albicans strains were typed by contour-clamped homogeneous electric field (CHEF) electrophoresis. Changes in strains were evaluated over time and in regard to their associations with particular sites, episodes of thrush, relapse after treatment, and colonization of sexual partners. Susceptibility to fluconazole was tested and CHEF analysis was done on these strains to determine the epidemiology of fluconazole resistance.

RESULTS: Yeasts colonized $84 \%$ of patients. $C$ albicans accounted for $81 \%$ of all isolates and was separated into 34 distinct strains. Most patients had persistent carriage of 1 or 2 dominant strains of $C$ albicans. Three couples shared strains. Nineteen different $C$ albicans strains caused 82 episodes of thrush in $\mathbf{4 5}$ patients. CD4 $<200 / \mu \mathrm{L}$ was associated with development of thrush. Clinical cure rates were similar with fluconazole (96\%) and clotrimazole $(91 \%)$, but mycologic cure was better with fluconazole $(49 \%)$ than clotrimazole $(27 \%)$. Following mycologic cure, colonization recurred with the same strain $74 \%$ of the time.

Colonization with Torulopsis glabrata and Saccharomyces cerevisiae increased after treatment with either drug, but these organisms were never a sole cause of thrush. In a subset of

From the Division of Infectious Diseases, Department of Internal Medicine, University of Michigan Medical School, and the Department of Veterans Affairs Medical Center, Ann Arbor, Michigan.

This study was supported hy a grant from Pfizer-Rnerig, Inc.

Requests for reprints should be addressed to Carol A. Kauffman, MD, Veterans Affairs Medical Center, 2215 Fuller Road, Ann Arbor, Michigan 48105

Manuscript submitted July 8, 1993 and accepted in revised form February 3, 1994
35 patients followed for over 3 months in whom fluconazole susceptiblities were performed, minimum inhibitory concentrations (MICs) to fluconazole increased only in those on fluconazole prophylaxis. Clinical failure of fluconazole was associated with an MIC $\geq 64$ $\mu \mathrm{g} / \mathrm{mL}$ in 3 patients, and with an MIC of $8 \mu \mathrm{g} / \mathrm{mL}$ in 1 patient. In 2 of these 4 patients, the prior colonizing strain developed fluconazole resistance. In the other 2 , new resistant strains were acquired.

CONCLUSIONS: Many different strains of $C$ albicans colonize and cause thrush in patients infected with HIV. Patients are usually persistently colonized with a single strain, and recurrences following treatment are usually due to the same strain. Transmission of strains may occur between couples. Fluconazole and clotrimazole are equally effective in treating thrush, but mycologic cure occurs more often with fluconazole.

Fluconazole resistance in $C$ albicans occurs most often in patients who have low CD4 counts and are taking fluconazole prophylactically for recurrent thrush. Fluconazole resistance may occur through acquisition of a new resistant strain or by development of resistance in a previously susceptible strain.

$\mathrm{O}$ ral candidiasis is the most common fungal infection in patients with human immunodeficiency virus (HIV) infection ${ }^{1,2}$ and is predictive of increasing immunosuppression., Although studies have assessed the prevalence, treatment, and prophylaxis of oral candidiasis, ${ }^{1-7}$ few have looked prospectively at the epidemiology of colonization and infection with Candida albicans and the effects of treatment on colonizing and infecting strains. ${ }^{8-15}$ 'I'hose studies that have been reported have shown widely divergent results.

Some studies have shown that patients with acquired immmunodeficiency syndrome (AIDS) have one predominant strain of $C$ albicans, ${ }^{9}$ but others have found multiple strains. ${ }^{10,11} \mathrm{~A}$ change in colonizing strains after treatment of thrush has bcen reported, ${ }^{11}$ and so has recurrence of the same strains. ${ }^{12,14}$ 
C albicans resistance to azole antifungal drugs has been described infrequently but appears to be increasing. ${ }^{15-18}$ The phenomenon of azole resistance has been seen almost entirely in AIDS patients receiving fluconazole for long-term therapy or prophylaxis for thrush. Most reports are isolated case reports. Few document susceptibility patterns before and after fluconazole therapy or relate such patterns to strain types. In one recent study from France, the authors showed development of resistance in the $C$ albicans strain causing thrush in 3 patients and acquisition of a new resistant $C$ albicans strain in another patient..$^{15}$ However, the authors gave few clinical details about these patients. A recent study from the United States, using DNA karyotyping, documented development of resistance to fluconazole in colonizing strains as well as acquisition of new resistant strains. ${ }^{18}$

In an attempt to define the epidemiology of oral candidiasis, we studied a cohort of 92 HIV-infected patients over the course of 1 year. $C$ albicans strains were karyotyped utilizing contour-clamped homogeneous electric field (CHEF) electrophoresis, ${ }^{19}$ one of several new techniques for typing $C$ albicans. ${ }^{19-22}$ Colonization and infection patterns, response to treatment, and effects of treatment on azole susceptibility were studied.

\section{PATIENTS AND METHODS}

\section{Patients}

Ninety-two men with HIV infection who were followed in the Infectious Diseases Clinic at the Ann Arbor Veterans Affairs Medical Center were enrolled in the study, which was conducted from July 1991 through June 1992. Samples for culture were taken from sexual partners of 10 of these patients to compare relatedness of colonizing $C$ albicans strains. All patients gave written informed consent prior to entry into the study.

\section{Clinical Parameters}

On admission to the study, patients were evaluated regarding classification of HIV infection (AIDS, AIDS-related complex [ARC], or asymptomatic by criteria established prior to January 1993), risk lactors for HIV infection, prior episodes of thrush, prior antifungal therapy, and CD4 lymphocyte subpopulations. Each time a patient was seen in clinic (usually monthly, but more often if they had thrush), he filled out a questionnaire regarding alcohol, cigarette, and drug use, oral hygiene measures (frequency of brushing, flossing, and using mouthwash), and sexual practices (frequency of oral, anal, or vaginal sexual intercourse, use of condoms, and number of partners). A careful examination was performed, including evaluation of lymph nodes and the oral cavity.

\section{Microbiologic Methods}

At initiation of the study, monthly thereafter, and whenever a patient had thrush, four oral sites (buccal mucosa, tongue, palate, and oropharynx) were swabbed with sterile rayon-tipped applicator sticks. The swabs were streaked directly onto one quadrant of a Sabouraud's dextrose agar plate containing $50 \mathrm{\mu g}$ gentamicin per mL. Within 1 to 2 hours, four-quadrant streaking with a loop was performed, and the plates were incubated at room temperature for 72 hours. Growth of yeasts was quantified (abundant, moderate, few, rare), different colony morphologies were noted, and single isolates of each colony type were subcultured onto Sabouraud's dextrose agar slants.

$C$ albicans was identified by germ tube formation after incubation for 2.5 hours at $37^{\circ} \mathrm{C}$ in bovine serum. Germ tube negative strains were speciated using the API 20C yeast identification system (Analytab Products, Inc., Plainview, New York). All isolates were stored frozen al $-70^{\circ} \mathrm{C}$ in Sabouraud's broth and glycerol for further studies.

\section{Preparation of $C$ albicans DNA}

Frozen stocks were thawed, streaked for isolation on Sabouraud's dextrose agar plates, and incubated for 18 hours at $37^{\circ} \mathrm{C}$. Yeast extract peptone dextrose (YEPD) broth, consisting of yeast extract $1 \mathrm{~g} / 100 \mathrm{~mL}$ (Difco, Inc., Detroit, Michigan), Bacto Peptone $1 \mathrm{~g} / 100$ $\mathrm{mL}$ (Difco), and dextrose $2 \mathrm{~g} / 100 \mathrm{~mL}$ in deionized, distilled $\mathrm{H}_{2} \mathrm{O}$ was inoculated with a single yeast colony and incubated for 48 hours at $37^{\circ} \mathrm{C}$ in $5 \% \mathrm{CO}_{2}$ atmosphere. The DNA was prepared as described by Schwartz and Cantor ${ }^{23}$ and modified by Vazquez et al. ${ }^{22}$

\section{CHEF Electrophoresis}

Portions of agarose plugs containing whole yeast cell DNA were loaded onto either a 15-lane or a 22lane horizontal electrophoresis gel prepared with 0.9\% ultrapure agarose (Biological Research Laboratories, Gaithersburg, Maryland) in 0.5x tris-borate EDTA (TBE) (Sigma) buffer. All gels contained chromosomal DNA from Saccharomyces cerevisiae ("Yeast chromosomal DNA," Bio-Rad, Richmond, California) as an internal standard. Chromosomal separation was achieved on a Bio-Rad CHEF DR-II apparatus using the following parameters: $165 \mathrm{~V}, 120-$ second switch time for 26 hours; followed by $125 \mathrm{~V}$, 250- to 400-second switch time for 28 hours; followed by $85 \mathrm{~V}, 750$ - to $900-$ second switch time for 26 hours. Running buffer was $0.5 \mathrm{x}$ TBE chilled to $13^{\circ} \mathrm{C}$ and changed with each change in parameters. Gels were stained with ethidium bromide, then photographed with ultraviolet transillumination. $C$ albicans strain differentiation was performed by delineation of the pattern of bands existing between 700 and 2,200 kilobases $(\mathrm{kb})$. For each isolate, the number of bands and 
their position relative to the $S$ cerevisiae standard bands were recorded. A library of banding patterns was established, and each isolate was given a code number, similar to the method of Pittet et al. ${ }^{19}$ A strain was considered unique if it had a different number of bands or a different position of these bands relative to all previously described banding patterns.

\section{Treatment of Thrush}

For study purposes, an episode of thrush required the presence of adherent white plaques on oral mucosal surfaces and growth of yeast on cultures obtained from the oral cavity. Erythematous candidiasis was not considered an episode because of concerns of objectively assessing the response to treatment. When thrush occurred, treatment group assignment was made based on the last digit of the patient's social security number. Patients were assigned to treatment with either oral fluconazole (200 $\mathrm{mg}$ initially followed by $100 \mathrm{mg}$ daily for a total of 14 days) or clotrimazole troches (10 $\mathrm{mg} 5$ times daily for 14 days). One day after the end of therapy for each episode (on day 15), each patient was evaluated for clinical cure (resolution of all objective findings of thrush) and mycologic cure (absence of yeast on culture of all 4 sites in the oral cavity).

Patients failing therapy by clinical parameters (persistence of plaques) were switched to the other drug and treated for 14 days. This occurred in only 2 patients. The episode was recorded as a failure for the initial drug given, and treatment with the second drug was evaluated as a new episode. Further episodes were treated with the drug to which the patient had been switched. Patients having 3 episodes of thrush were put on prophylaxis with either clotrimazole or fluconazole and removed from the treatment study. Cultures were performed intermittently in those on prophylaxis to determine colonizing strains.

\section{Fluconazole Susceptibility Studies}

Isolates from a subset of patients who received treatment for thrush were characterized in regard to susceptibility to fluconazole. The patients in whom susceptibility lests were performed were those who had $C$ albicans isolated prior to and/or at a first episode of thrush, follow-up for more than 3 months, and subsequent isolation of $C$ albicans on follow-up cultures after treatment.

Fluconazole susceptibilities were performed using a broth macrodilution system as recommended by the National Committee for Clinical Laboratory Standards. ${ }^{24-26}$ After growth on Sabouraud's dextrose agar plates for 24 hours, organisms were inoculated into tubes containing RPMI-1640 (Roswell Park Medical Institute, Buffalo, New York) medium-buffered to a

\begin{tabular}{|c|c|}
\hline \multicolumn{2}{|c|}{$\begin{array}{l}\text { Patient Characteristics } \\
\text { at the Time of Entry into the Study }\end{array}$} \\
\hline Characteristic & Number $(\%)$ \\
\hline \multicolumn{2}{|l|}{ Risk factors for HIV } \\
\hline Homosexual male & $76(83)$ \\
\hline Injectable drug use & $12(13)$ \\
\hline Heterosexual & $4(4)$ \\
\hline \multicolumn{2}{|l|}{ Classification of HIV } \\
\hline AIDS & $26(28)$ \\
\hline AIDS-related complex & $28(31)$ \\
\hline Asymptomatic & $38(41)$ \\
\hline \multicolumn{2}{|l|}{ CD4 cell number } \\
\hline$<50$ & $21(23)$ \\
\hline $50-200$ & $16(17)$ \\
\hline $200-500$ & $31(34)$ \\
\hline$>500$ & $24(26)$ \\
\hline
\end{tabular}

final $\mathrm{pH}$ of 7.0 with MOPS, achieving a final inoculum of approximately $2 \times 10^{3}$ organisms per $\mathrm{mL}$. Fluconazole concentrations ranged from $0.12 \mu \mathrm{g} / \mathrm{mL}$ to $64 \mu \mathrm{g} / \mathrm{mL}$. The endpoint, minimal inhibitory concentration (MIC), was read after 48 hours as an $80 \%$ decrease in growth, as described by Espinel-Ingroff, et al. ${ }^{26}$

\section{Statistical Analysis}

Differences in outcome related to treatment and significance of risk factors for development of thrush were analyzed by the chi-square test.

\section{RESULTS}

\section{Patients}

The mean age of the 92 men at entry into the study was $38.5 \pm 0.9$ years. As noted, $26(28 \%)$ had AIDS, 28 (31\%) had ARC, and 38 (41\%) were asymptomatic (Table I). They were followed for a mean of $8.2 \pm 0.4$ months. At the end of the study, HIV status was again evaluated for each patient. In some cases, this was prior to June 1992 because patients moved (12), died (8), or developed another fungal infection requiring systemic antifungal treatment (2). At study termination, 37 (40\%) had AIDS, 31 (34\%) had ARC, and only 24 (26\%) remained asymptomatic.

\section{Colonization With Yeasts}

Altogether, 77 of the 92 patients (84\%) had yeasts grown from their oral cavity on at least 1 occasion during the study. Of the 2,784 cultures performed, $1,620(58 \%)$ yielded yeasts, and a total of 1,965 isolates were recovered. $C$ albicans was the predominant isolate. It accounted for $81 \%$ of all isolates, was present in $83 \%$ of all patients, and occurred in 76 of 77 patients whose cultures yielded yeasts (Table II). 


\begin{tabular}{|c|c|c|}
\hline \multicolumn{3}{|l|}{ TABLE II } \\
\hline $\begin{array}{l}\text { Yeasts } \\
\text { Isolated }\end{array}$ & $\begin{array}{l}\text { Number }(\%) \\
\text { of Patients* }\end{array}$ & $\begin{array}{l}\text { Number (\%) } \\
\text { of all Isolates }\end{array}$ \\
\hline Candida albicans & $76(83)$ & $1,588(81)$ \\
\hline Torulopsis glabrata & $13(14)$ & $182(9)$ \\
\hline Saccharomyces cerevisiae & $10(11)$ & $91(5)$ \\
\hline Candida stellatoidea & $10(11)$ & $21(1)$ \\
\hline Candida tropicalis & $2(2)$ & $20(1)$ \\
\hline Other Candida species ${ }^{\dagger}$ & $10(11)$ & $14(1)$ \\
\hline Non-Candida species ${ }^{\ddagger}$ & $17(18)$ & $49(2)$ \\
\hline \multicolumn{3}{|c|}{$\begin{array}{l}\text { Patients often had more than one species isolated; } 15 \text { patients never } \\
\text { had a positive culture for yeast. } \\
\text { IIncludes C. parapsilosis, C. paratropicalis, and C. rugosa. } \\
\text { Includes Blastoschizomyces capitatus, Cryptococcus laurentii, } \\
\text { Cryptococcus uniguttulatus, Sporobolomyces salmonicolor, and } \\
\text { Prototheca zopfii. }\end{array}$} \\
\hline
\end{tabular}

The next most commonly isolated yeasts were Torulopsis glabrala and Saccharomyces cerevisiae. Only 15 of 92 patients (16\%) remained negative for yeasts in their oral cavity throughout the study. Ten of these 15 had asymptomatic HIV infection, 4 had $\Lambda \mathrm{RC}$, and 1 had $\Lambda \mathrm{IDS}$. Ten had CD4 counts $>500 / \mathrm{\mu L}$, and 5 had between 200 and $500 \mathrm{CD} 4$ cells/ $/ \mathrm{LL}$.

The only risk factor found to be significantly associated with colonization with yeasts was a CD4 count $<500 / \mu \mathrm{L}$. $(P<0.0001)$. Alcohol, drug, or cigarette use, oral hygiene practices, and sexual practices were not associated with colonization.

\section{Typing of $C$ albicans Colonizing Strains}

Sixty-six of the 76 patients with $C$ albicans had typing of their isolates performed. Isolates from several patients seen only once were not typed, and several isolates were lost in the laboratory.

The total number of different strains of $C$ albicans carried over the course of the year by the 66 patients whose isolates were typed was 34 . One strain was most common. It was cultured from at least 1 site on at least 1 occasion from 49 (74\%) of the 66 , and found in 428 of 918 (47\%) typings.

Among 52 patients who either never received antifungal therapy or who had cultures performed on 2 or more occasions prior to therapy, 24 (46\%) had persistent carriage of only 1 strain. Another 7 patients (14\%) were colonized with 1 dominant strain, but also transiently carried other strains on 2 or more occasions. Twenty-one patients ( $40 \%$ ) had 2 or 3 dominant strains of $C$ albicans present at all times.

There were 45 patients who grew $C$ albicans from all 4 oral sites on the first day that cultures were performed and had these isolates typed. Twenty-six (58\%) had the same strain present in all 4 sites, 17 (38\%) showed 2 different strains, and 2 (4\%) showed 3 different strains at these different sites.

\section{Episodes of Infection}

Forty-five patients had 82 episodes of thrush over the course of the study. Twenty-six of them (58\%) had AIDS, 15 (33\%) had ARC, and 4 (9\%) were asymptomatic at the time they developed thrush. The only risk factor found to be important for the development of thrush was a CD4 count $<200 / \mu \mathrm{L}(P<0.0001)$. There were no associations with the use of cigarettes, alcohol, drugs, sexual practices, or oral hygiene.

Objective evidence of thrush was strongly associated with an increase in the number of sites in the oral cavity yielding $C$ albicans $(P<0.0001)$ and with abundant growth in culture $(P<0.0001)$. All episodes of thrush were associated with $C$ albicans, which was the sole pathogen in 63 episodes, and was mixed with other yeasts-usually $T$ glabrata or $S$ cerevisiae -in 19.

The $C$ albicans strains were typed in 74 episodes of thrush. The most common colonizing strain was found in 41 (55\%), and the second most conmon in 22 episodes (30\%). Altogether, a total of 19 different strains caused the 74 episodes of thrush. In 51 episodes (69\%), only 1 strain was present at the time of infection; in 18 episodes (24\%), 2 different strains were present; and in 5 (7\%), there were 3 different strains. In only 2 patients were the initial colonizing strains different from those that later caused the first episode of thrush.

\section{Response to Treatment}

Twenty-three patients were randomized to treatment with fluconazole and 22 to treatment with clotrimazole. The 2 treatment groups did not differ in regard to risk group for HIV infection, stage of HIV disease, or CD4 counts. Overall, the clinical response to therapy was excellent for both fluconazole ( $96 \%$ cure) and clotrimazole (91\% cure) (Table III). The mycologic cure rate was lower with clotrimazole (27\%) than with fluconazole (49\%), but this difference was not statistically significant. Relapse of thrush within 2 weeks of completion of treatment occurred after 7 episodes treated with clotrimazole and after only 2 episodes treated with fluconazole. Adverse effects did not occur with clotrimazole, and one patient developed a rash while on fluconazole.

\section{Colonization Following Treatment}

Seventeen patients in whom therapy eradicated yeast were followed for at least 2 months posttreatment. In this group, colonization with $C$ albicans recurred after each of 23 episodes of thrush. After 17 episodes (74\%), recolonization was due to the same $C$ albicans strain which caused the infection. In 3 instances (13\%), a new $C$ albicans strain occurred along with the prior strain, while, in an- 


\section{TABLE III}

Results of Treatment of Thrush With Fluconazole or Clotrimazole Troches

\begin{tabular}{lcc}
\hline & Fluconazole & Clotrimazole \\
\hline Number of patients randomized to treatment group & 23 & 22 \\
Number of patients crossed over from other drug after first episode & 4 & 1 \\
Number of episodes treated & 47 & 35 \\
Clinical cure $^{\dagger}$ & $45 / 47(96 \%)$ & $31 / 34(91 \%)$ \\
Mycologic cure & $22 / 45(49 \%)$ & $9 / 33(27 \%)$ \\
\hline
\end{tabular}

"Patients crossed over from clotrimazole to fluconazole for treatment of subsequent episodes because of failure (2), presence of esophagitis on second episode (1), and investigator error (1). One patient crossed over from fluconazole to clotrimazole for treatment of a second episode because of development of a rash possibly due to fluconazole.

tClinical response not known for 1 patient receiving clotrimazole because of death from myocardial infarction on day 7 of therapy.

${ }_{+}$Cultures not performed at the end of an episode of thrush in 2 patients in each group.

other 3, a totally new $C$ albicans strain appeared following treatment (Figure 1).

New species of yeasts emerged following treatment of 24 episodes of thrush in 14 patients. After 10 episodes in 8 patients, $T$ glabrata emerged as the domirlant yeast in the oral cavily. Five of the 10 had been treated with fluconazole and 5 with clotrimazole. S cerevisiae also occurred following treatment. One patient received fluconazole on 2 occasions and both times had emergence of $S$ cerevisiae as the dominant species. Another patient was treated 3 times with clotrimazole, and each time $S$ cerevisiae emerged as the sole yeast in the oral cavity. The remaining 4 patients had new Candida species isolated transiently following treatment. In contrast, only 2 patients who had never received antifungal therapy had colonization with $T$ glabrata or $S$ cerevisiae over the course of the study.

\section{Strain Relatedness in Sexual Partners}

In 4 couples with 1 partner who was HIV-negative, only $1 \mathrm{HIV}$-negative partner had yeast cultured from the oral cavity. In 5 of 6 couples where both partners were HIV-positive, both partners had yeasts cultured from their oral cavity. The same $C$ albicans strains were isolated from both partners in 3 of these couples, and different strains in 2. In 1 couple who originally were colonized with the same strain, 1 partner became colonized by a new strain after treatment with fluconazole. In another couple who shared 2 strains, the dominant strain in the partner who had been treated with fluconazole was resistant to the drug. This strain ultimatcly became dominant in the other partner, but only after he, too, was treated with fluconazole.

\section{Fluconazole Susceptibilities}

Over the course of the year, a subset of 35 patients meeting criteria described in the Methods section had fluconazole susceptibilities and CHEF typing determined for 213 unique $C$ albicans isolates, excluding identical strains isolated from multiple oral sites on the same day. Strains isolated prior to therapy for

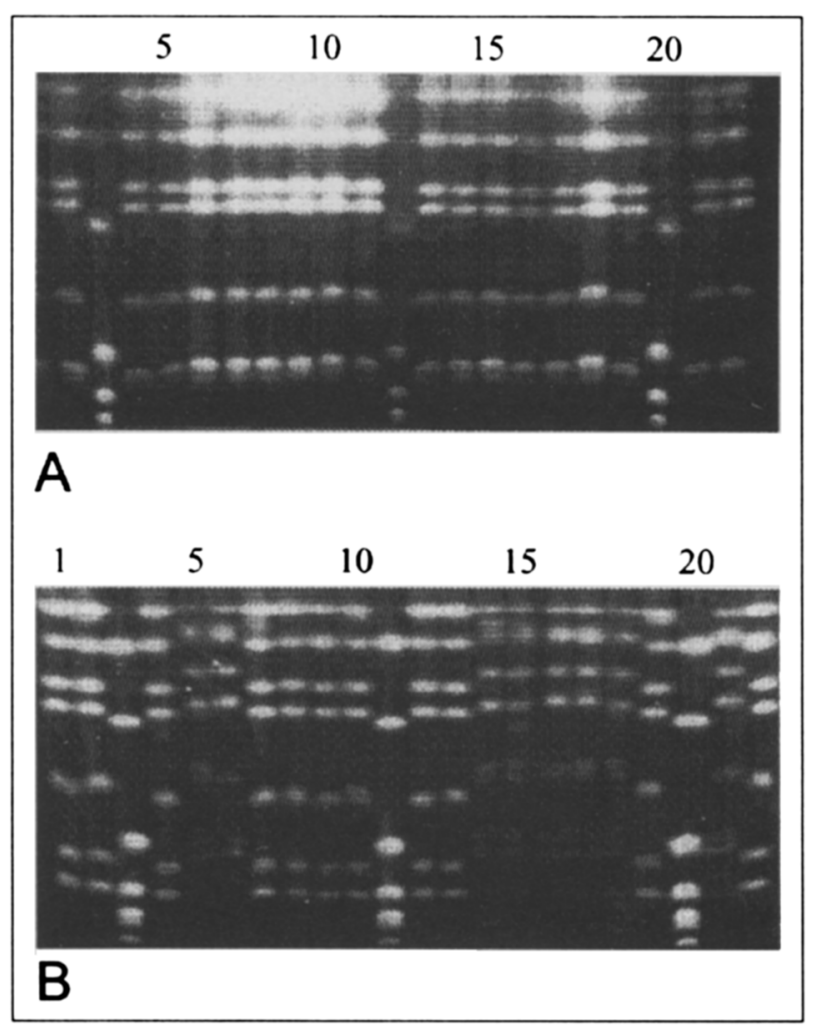

Figure 1. A. CHEF electrophoresis pattern of isolates from a patient who did not demonstrate a change in $C$ albicans strains following treatment of thrush with clotrimazole troches. Lanes 2,4 and 5 are isolates from the first episode of thrush, lanes 6-11 are isolates from the second episode of thrush 1 month later, and lanes 13-19 and 21-22 are isolates from the third episode of thrush and subsequent colonizing strains during daily prophylaxis with clotrimazole. Lanes 3, 12, and 20 are the Saccharomyces cerevisiae standard. All strains appear to be identical and represent the most common strain found in this study. B. CHEF electrophoresis pattern of isolates from a patient who had recurrent thrush with new strains of $C$ albicans following treatment of thrush with fluconazole. Lanes 1,2 , and 4 are isolates from this patient's second episode of thrush; lanes 5-7 are from posttreatment cultures following treatment and show the same strain as before (lane 7) and 2 new strains (lanes 5 and 6). Lanes 8-10 and 12-13 are isolates from the third episode of thrush and are the same as those which caused thrush during the second episode 2 months previously. Lanes $14-19$ and $21-22$ show 4 different strains, one of which is the original strain, which emerged following therapy and during prophylaxis with fluconazole. Lanes 3, 11 , and 20 are the $S$ cerevisiae standard. CHFF $=$ contourclamped homogeneous electric field. 


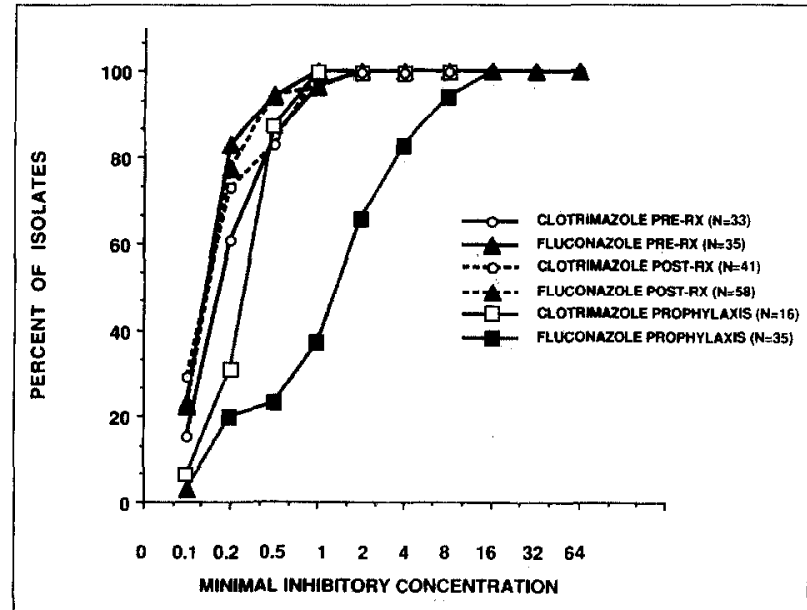

Figure 2. Minimum inhibitory concentrations (MICs) for 213 isolates from 35 patients treated for thrush. The percent of isolates at each MIC are shown. $\mathrm{Rx}=$ treatment

thrush with clotrimazole (16) or fluconazole (15), following therapy with clotrimazole (14) or fluconazole (21), and following prophylaxis with clotrimazole (4) or fluconazole (9) were compared in regard to MICs for fluconazole (Figure 2).

Only strains from patients receiving fluconazole for prophylaxis changed MICs. The MIC required to inhibit $90 \%$ of the isolates $\left(\mathrm{MIC}_{90}\right)$ increased from 0.5 $\mu \mathrm{g} / \mathrm{mL}$ prior to and after arute therapy to $8 \mu \mathrm{g} / \mathrm{mL}$ following prophylaxis for a mean of 4.3 months. There were no changes in fluconazole MICs in patients on prophylaxis with clotrimazole.

Within this subset of 35 patients, 4 had recurrent thrush during the year of the study and after. Three of the 4 were on fluconazole chronically and had CD4 counts $<20 / \mu \mathrm{L}$ for more than 1 year. $C$ albicans continued to be the only organism isolated when they had thrush. Fluconazole MICs and CHEF typing were performed on all isolates from these 3 patients. The MICs for early isolates were 0.2 to $0.5 \mu \mathrm{g} / \mathrm{mL}$. The MICs were $\geq 64 \mu \mathrm{g} / \mathrm{mL}$ when the patients had thrush unresponsive to fluconazole.

These patients initially responded to higher doses of fluconiazole. All required $800 \mathrm{mg}$ of the drug daily, but all ultimately failed to respond to this dose. Two were subsequently treated successfully with intravenous amphotericin $B$. One maintained the same CHEF strain throughout the entire period of study, which appeared to have developed fluconazole resistance (Figure 3). One acquired a new strain, which persisted and was fluconazole-resistant in vitro. The third had 4 sensitive strains, of which 3 disappeared and the fourth developed resistance to fluconazole and persisted.

The fourth patient with recurrent thrush had a CD4 count of $270 / \mu \mathrm{L}$ and was not on chronic fluconazole when he acquired a new strain with an MIC of $8 \mu \mathrm{g} / \mathrm{mL}$ and clinical failure occurred. He appeared to have acquired the resistant strain from his sexual partner. The partner had taken fluconazole chronically, had thrush unresponsive to fluconazole, and had isolation of 2 resistant strains. Our patient subsequently lost this strain, and later episodes of thrush responded to fluconazole (Figure 3).

\section{COMMENTS}

This prospective study of 92 patients has helped define the epidemiology of oral candidiasis, the most common fungal infection in HIV-positive patients. We found, as have others, that colonization and subsequent infection was associated with diminishing CD4 cell counts. ${ }^{1-3}$ Sexual practices, oral hygiene measures, alcohol, drug, and cigarette use were not associated with colonization or infection. The overall colonization rate of $84 \%$ was elevated compared with normal populations or hospitalized patients, in whom rates are usually $40 \%$ to $60 \% .27,28$

Although we found that 1 strain of $C$ albicans was more common than others, we identified 34 different strains in this cohort of patients. Some investigators have reported finding 1 dominant strain in HIV-positive patients, ${ }^{9}$ but most studies have shown that AIDS patients harbor many different strains of $C$ albicans. ${ }^{10,11,13,14}$ In general, studies that use molecular typing methods rather than biotyping methods have found a greater number of unique strains. ${ }^{12-14}$

Symptomatic thrush occurred only when $C$ albicans was present. When another yeast was present along with $C$ albicans, it was impossible to know if one or both were responsible for symptoms. However, no patient had symptomatic thrush at a time when only non-albicans species were present. In contrast, a report by Powderly ${ }^{29}$ noted that $T$ glabrata, Candida parapsilosis, Candida krusei, and Candida tropicalis can cause thrush in HIV-positive patients. JustNübling et $\mathbf{a l}^{30}$ found that Candida famata and $T$ glabrata were associated with typical thrush in 1 patient each, both of whom had been treated with fluconazole previously. Although we frequently noted colonizalion wilh $T$ glabrala in palients who had been treated with either fluconazole or clotrimazole, recurrent thrush in these patients was always associated with recovery of $C$ albicans in culture.

We found that after antifungal therapy, the strain that caused the infection was usually the one to recolonize. New strains emerged in a few cases. Previous studies have yielded contradictory results on this issue, with Bruatto et al $^{11}$ showing new strains occurring after treatment, and Schmid et $\mathrm{al}^{12}$ and Miyasaki et $\mathrm{al}^{14}$ finding the same strains.

Colonization of sexual partners by $C$ albicans depended on HIV status. Partners who were HIV-negative remained free of $C$ albicans. Three HIV-positive 
couples were colonized with the same strain or combination of strains of $C$ albicans. In one of these couples, in which both partners carried the same two strains, treatment of our patient with fluconazole was associated with a switch from his dominant strain to the dominant strain carried by his partner, who had previously received fluconazole. These findings are similar to those of Miyasaki et al, ${ }^{14}$ who found possible transmission of strains from partner to partner.

Both clotrimazole troches and oral fluconazole were effective for treatment of thrush, but fluconazole produced mycologic cure more often than did clotrimazole. Relapses within a few weeks were more often noted after treatment with clotrimazole, a finding also noted by Koletar et al. ${ }^{7}$ Emergence of new species of yeast, especially ' $T$ ' glabrata and $S$ cerevisiae, was seen after treatment with either fluconazole or clotrimazole. Most likely this reflects the relatively greater resistance of these species to azole antifungal drugs. ${ }^{31,32}$ We did not see the emergence of C kruse in our patients, although this event has been noted in bone marrow transplant recipients receiving fluconazole chronically. ${ }^{33}$

Our finding that $C$ albicans strains became more resistant to fluconazole is worrisome. Increasing resistance in vitro correlated with clinical failure in 1 patients who were followed for 2 years. In 2 patients, it appeared that resistance developed in a strain which had previously been susceptible to fluconazole. Bart-Delabesse et al ${ }^{15}$ made a similar finding in 3 of 4 AIDS patients, as did Pfaller et al ${ }^{18}$ in 1 of 29 AIDS patients. Initially, 3 of our patients responded to higher doses of fluconazole; but when the MIC exceeded $64 \mu \mathrm{g} / \mathrm{mL}$ clinical failure occurred despite dosages of $800 \mathrm{mg} / \mathrm{d}$. Redding et $\mathrm{al}^{34}$ have reported a similar experience. $\mathrm{Ng}$ and Denning ${ }^{35}$ have discussed the problem of fluconazole resistance in AIDS patients and offered several treatment options, including ketoconazole or itraconazole, but amphotericin B has usually been required.

Development of methods for differentiating strains of $C$ albicans at a genetic level has facilitated definition of the epidemiology of colonization in several different settings. ${ }^{19,36-40} \mathrm{CHEF}$ methodology was used by Piltei el al ${ }^{19}$ to type Candida isolates from patients in intensive care units and by Pfaller et al $^{18}$ with isolates from AIDS patients with thrush. Schmid et $\mathrm{al}^{37}$ used Southern blot hybridization procedures to probe for repetitive DNA sequences in a variety of different patient populations colonized with $C$ albicans. Others have used restriction fragment enzyme analysis for epidemiologic studies of nosocomial acquisition of $C$ albicans. ${ }^{39,40}$

These different molecular typing methods have proved useful in studies of the epidemiology of $C . a l$ bicans colonization in patients with HIV infec-

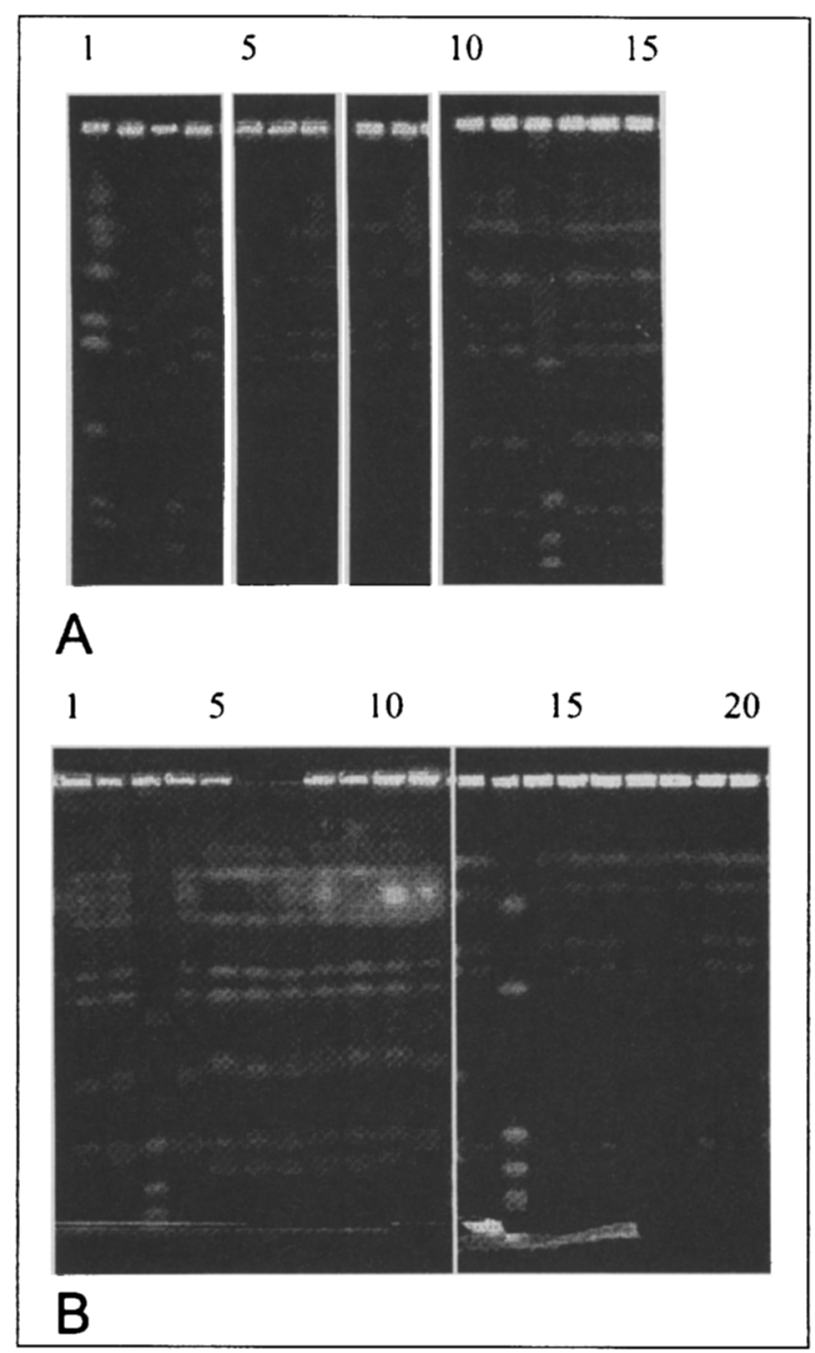

Figure 3. A. CHEF electrophoresis pattern of strains of Candida albicans from a patient who developed clinical failure after chronic fluconazole use. Lanes 1, 2, and 4 are from March 1992 and have MICs of 1-2 $\mu \mathrm{g} / \mathrm{mL}$. Lanes 5-7, from April 1992, have MICs of 0.5$2 \mu \mathrm{g} / \mathrm{mL}$. Lanes 8-9, from May 1992, have MICs of $16 \mu \mathrm{g} / \mathrm{mL}$. Lanes 10-11, from February 1993, have MICs $>64 \mu \mathrm{g} / \mathrm{mL}$. Lanes 13-15, from April 1993, have MCs $>64 \mu \mathrm{g} / \mathrm{mL}$. Lane 3 and 12 are the Saccharomyces cerevisiae standard. All isolates are the same strain. In February and again in April 1993, the patient had thrush while taking fluconazole $800 \mathrm{mg} / \mathrm{d}$. B. CHEF electrophoresis pattern of isolates from a patient who acquired a new fluconazole resistant strain of $\mathrm{C}$ albicans from his sexual partner. Lanes 1, 2, and 4 were isolated in February 1992 from our patient's sexual partner and are 2 different strains, both with MICs of $16 \mu \mathrm{g} / \mathrm{mL}$. Lanes $5-10$ are from our patient from November 1991 to February 1992 and are the same strain, all with MICs of $0.2-2 \mu \mathrm{g} / \mathrm{mL}$. Lane 11, from April 1991, is the same strain the patient's partner carried, and the MIC is $8 \mu \mathrm{g} / \mathrm{mL}$. Lanes 12 and 14-20, from May and June 1992, the same strain again, have MICs of $4-8 \mu \mathrm{g} / \mathrm{mL}$, and were associated with failure of 200 $\mathrm{mg}$ of fluconazole daily. Lanes 3 and 13 are the $S$ cerevisiae standard. $\mathrm{CHEF}=$ contour-clamped homogeneous electric field. $\mathrm{MIC}=$ minimum inhibitory concentration .

tion. ${ }^{12-15,18}$ In our study and several prior studies, these techniques have helped establish the number of colonizing and infecting strains in patients with $\mathrm{HIV},{ }^{13,14,18}$ the transmission of these strains from partners, ${ }^{14}$ and the role of different strains in recrudes- 
cent infection. ${ }^{12,14,15,18}$ DNA typing methods other than $\mathrm{CHEF}$, or in combination with $\mathrm{CHEF}$, very likely might have increased sensitivity for detection of strain differences. As these techniques become more refined, they should allow us to address further the important questions of whether azole resistance is due to changes in colonizing strains or acquisition of new strains, whether azole-resistant strains can be passed from patient to patient, and what influence the use of prophylactic antifungal drugs has on the spread of azole-resistant strains.

\section{ACKNOWLEDGMENT}

This study was supported by a grant from Pfizer-Roerig, Inc.

\section{REFERENCES}

1. Klein RS, Harris CA, Small CB, et al. Oral candidiasis in high-risk patients as the inital manifestation of the acquired immunodeficiency syndrome. NEJM. 1984;311:354-358.

2. Feigal DW, Katz MH, Greenspan D, et al. The prevalence of oral lesions in HIV-infected homosexual and bisexual men: three San Francisco epidemiological cohorts. AlDS. 1991;5:519-525.

3. Phair JP, Munoz A, Detels $R$, et al. The risk of Pneumocystis carinii pneumoria annung men infected wilh hurıan ienrrunodeficiency virus lype 1. NEJM. 1990;322:161-165.

4. Rothenberg $R$, Woelfel $M$; Stoneburner $R$, et al. Survival with the acquired immunodeficiency syndrome. Experience with 5833 cases in New York City. NEJM. 1987;317:1297-1302.

5. Sleveris DA, Greerı I, Lang OS. Thrushı can! be prevented in palienls wilh acquired immunodeficiency syndrome and the acquired immunodeficiency syndrome-related complex. Arch intern Med. 1991;151:2458-2464.

6. De Wit D, Weerts D, Goossens H, Clumeck N. Comparison of fluconazole and ketoconazole for oropharyngeal candidiasis in AIDS. Lancet. 1989;1:746-747.

7. Kolelar SL, Russell JA, Fass RJ, Ploulfe JF. Cornparison of oral flucurlazule and clotrimazole troches as treatment for oral candidiasis in patients infected with human immunodeficiency virus. Antimicrob Agents Chemother. 1990;34:2267-2268.

8. Brawner DL, Cutler JE. Oral Candida albicans isolates from nonhospitalized numal carriers, imnunocompelenl huspitalized patienls, and immunocompromised patients with or without acquired immunodeficiency syndrome. J Clin Microbiol. 1989;27:1335-1341.

9. Korting $\mathrm{HC}$, Ollert $M$, Georgii A, Froschl M. In vitro susceptibilities and biotypes of Candida albicans isolates from the oral cavities of patients infected with human irminutodeficien icy virus. J Clin Microbsul. 1988;26:2626-2631.

10. Whelan WL, Kirsch DR, Kwon-Chung KJ, et al. Candida albicans in patients with the acquired immunodeficiency syndrome: Absence of a novel or hypervirulent strain. J Infect Dis. 1990;162:513-518.

11. Bruatto $M$, Vidotto $V$, Marinuzzi $G$, et al. Candida albicans biotypes in human immunodeficiency virus type 1 -infected patients with oral candidiasis before and after antifungal therapy. J Clin Microbiol. 1991;29:726-730.

12. Schmid J, Odds FC, Wiselka MJ, et al. Genetic similarity and maintenance of Candida albicans strains from a group of AIDS patients, demonstrated by DNA fingerprinting. J Clin Microbiol. 1992;30:935-941.

13. Powderly WG, Robinson K, Keath EJ. Molecular typing of Candida albicans isolated from oral lesions of HIV-infected individuals. AIDS. 1992;6:81-84.

14. Miyasaki SH, Hicks JB, Greenspan D, et al. The identification and tracking of Candida albicans isolates from oral lesions in HIV-seropositive individuals. $J$ Acquir Immune Defic Syndr. 1992;5:1039-1046.

15. Bart-Delabesse E, Boiron P, Carlotti A, Dupont B. Candida albicans genotyping in studies with patients with AIDS developing resistance to fluconazole. J Clin Microbiol. 1993:31:2933-2937.

16. Fox R, Neal KR, Leen CLS, et al. Fluconazole resistant candida in AIDS. J infect. 1991;22:201-204.
17. Kitchen VS, Savage M, Ilarris JRW. Candida albicans resistance in AIDS. $J$ Infect. 1991;22:204-205.

18. Pfaller MA, Rhine-Chalberg J, Redding SW, et al. Variations in fluconazole susceptibility and electrophoretic karyotype among oral isolates of Candida albicans from patients with AIDS and oral candidiasis. J Clin Microbiol. 1994:32:59-64.

19. Pittet $D$, Monod M, Filthuth I, et al. Contour-clamped homogeneous electric field gel electrophoresis as a powerful epidemiologic tool in yeast infections. Am J Med. 1991;91(suppl 3B):256S-263S.

20. Pfaller MA. Epidemiological typing methods for mycoses. Clin Infect Dis. 1992;14(suppl 1):S4-\$10.

21. Magee PT, Bowdin L, Staudinger J. Comparison of molecular typing methods for Candida albicans. J Clin Microbiol. 1992:30:2674-2679.

22. Vazquez JA, Beckley A, Sobel JD, Zervos MJ. Comparison of restriction enzyme analysis and pulsed-field gradient gel electrophoresis as typing systems for Candida albicans. J Clin Microbiol. 1991;29:962-967.

23. Schwartz DC, Cantor CR. Separation of chromosome-sized DNAs by pulsed field gradient gel electrophoresis. Cell. 1984;37:67-75.

24. National Committee for Clinical Laboratory Standards. 1992. Reference method for broth dilution antifungal susceptibility testing for yeasts. Proposed Standard Document M-27P. Villanova, Pennsylvania: National Committee for Clinical Laboratory Standards.

25. Fromtling RA, Galgiani JN, Pfaller MA, et al. Multicenter evaluation of a broth macrodilution antifungal susceptibility test for yeasts. Antimicrob Agents Chemother. 1993:37:39-45.

26. Espine-Ingroff $A$, Kish $C W$, Kerkering $T M$, et al. Collaborative comparison of broth macrodilution and microdilution antifungal susceptibility tests. J Clin Microbiol. 1992;30:3138-3145.

27. Odds FC, Evans EGV. Distribution of pathogenic yeasts and humoral antibodies to Candida among hospital inpatients. J Clin Pathol. 1980:33:750-756.

28. Mackenzie DWR. Yeasts from human sources, Sabouraudia. 1961;1:8-15. 29. Powderly WG. Mucosal candidiasis caused by non-albicans species of Candida in HIV-positive patients. AIDS. 1992;6:604-605.

30. Just-Nübling $G$, Gentschew $G$, Döhle $M$, et al. Fluconazole in the treatment of oropharyngeal candidiasis in HIV-positive patients. Mycoses. 1990:33:435-440.

31. Morace G, Manzara S, Dettori G. In vitro susceptibility of 119 yeast isolates to fluconazole, 5-flucytosine, amphotericin B, and ketoconazole. Chemotherapy. 1991;37:23-31.

32. Odds FC. Antifungal susceptibility testing of Candida by relative growth measurement at single concentrations of antifungal agents. Antimicrob Agents Chemother. 1992;36:1727-1737.

33. Wingard JR, Merz WG, Rinaldi MG, et al. Increase in Candida krusei infection among patients with bone marrow transplantation and neutropenia treated prophylactically with fluconazole. NEJM. 1991;325:1274-1277.

34. Redding S, Smith J, Farinacci G, et al. Resistance of Candida albicans to fluconazole during treatment of oropharyngeal candidiasis in a patient with AIDS: documentation by in vitro susceptibility testing and DNA subtype analysis. Clin Infect Dis. 1994:18:240-242.

35. Ng TTC, Denning DW. Fluconazole resistance in Candida in patients with AIDS: a therapeutic approach. J Infect. 1993;26:117-125.

36. Merz WG. Candida albicans strain delineation. Clin Microbiol Rev. 1990:3:321-334.

37. Schmid J, Voss E, Soll DR. Computer-assisted methods for assessing strains relatedness in Candida albicans by fingerprinting with the moderately repetitive sequence Ca3. J Clin Microbiol. 1990;28:1236-1243.

38. Fox BC, Mobley HLT, Wade JC. The use of a DNA probe for epidemiological studies of candidiasis in immunacompromised hosts. $J$ Infect Dis. 1989:159:488-494.

39. Doebbeling $B N$, Hollis RJ, Isenberg $H D$, et al. Restriction fragment analysis of a Candida tropicalis outbreak of sternal wound infections. J Clin Microbiol. 1991;29:1268-1270.

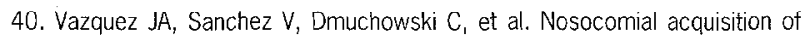
Candida albicans: an epidemiologic study. J Infect Dis. 1993;168:195-201 